\title{
Staying together or breaking apart: Policy-makers' endogenous coalitions formation in the European Economic and Monetary Union*
}

\author{
Bas van Aarle \\ University of Leuven and University of Nijmegen \\ Giovanni Di Bartolomeo \\ University of Antwerp and University of Rome "La Sapienza" \\ Jacob Engwerda \\ Tilburg University \\ Joseph Plasmans \\ University of Antwerp and Tilburg University
}

March 2002

\begin{abstract}
In this paper, we analyze coordination of macroeconomic stabilization policies within the EMU by focusing, in a dynamic set-up, on asymmetries, externalities, and the existence of a multi-country context. We study how coalitions among fiscal and monetary authorities are formed and what are their effects on the stabilization of output and price. In particular, our attention is directed to study the consequences on these issues of different institutional contexts in which policy-makers may act. Among other results, we found that, in the presence of externalities, the occurrence of asymmetries is a necessary but not a sufficient condition for cooperation.
\end{abstract}

JEL codes: C70, E17, E58, E61, E63.

Keywords: Macroeconomic stabilization, EMU, coalition formation.

${ }^{*}$ We are grateful to seminar participants at the University of Antwerp. Bas van Aarle and Giovanni Di Bartolomeo acknowledge the financial support from the FWO (Fund for Scientific Research) in Flanders and the BOF (Special Research Fund) of the University of Antwerp, respectively. 


\section{Introduction}

The European Economic and Monetary Union (EMU) is a highly integrated economic area with a large number of interactions between the participating countries. Given the presence of externalities, the design of macroeconomic stabilization policies is a crucial issue. In the literature on macroeconomic policy analysis, the issue of coordination of stabilization policies has been an important aspect. ${ }^{1}$ The coordination of macroeconomic policies concerns (i) the issue of coordination of monetary and fiscal policies and (ii) the coordination of stabilization policies among different countries. Most studies use static models, in which generally only two (often symmetric) countries act. In the EMU case, most of these studies argue that the introduction of the EMU, which implies a common monetary policy and restrictions on fiscal policy at the national level, increases the need for macroeconomic policy cooperation due to the various interactions and externalities from national macroeconomic policies. However, given the potentially adverse reaction by the European Central Bank (ECB), as a result of free-riding and/or a conflict on the orientation of the policy mix, fiscal coordination might likely be counterproductive. The introduction of a third player may have dramatic effects on the standard propositions based on a two-country model. ${ }^{2}$ For example, Rogoff (1985) and Kehoe (1988) suggest that, in this case, cooperation may be counterproductive since the introduction of a third player may turn the prisoners' dilemma in a deadlock game. ${ }^{3}$ Different types of games are mutually compared by Carraro (1997).

Although the usefulness of studying macroeconomic stabilization in a dynamic context is well known in the literature ${ }^{4}$, almost all studies related to a common monetary area use a static model to derive policy recommendations. This paper analyzes the design of macroeconomic stabilization policies and their coordination in EMU using an explicit dynamic structure in which all aspects of policy coordination have an explicit time and timing dimension. In particular, policy strategies, the externalities and the payoffs obtained by a coalition of the policy-makers who coordinate their policies depend crucially on the other policy-makers' behavior over time in this dynamic approach.

Coordination of (national) fiscal policies and (a common) monetary policy will be investigated by focusing on the role played by: i) asymmetries (in structural and preference parameters), ii) externalities, which are the key to endogenously explain the coalition formation, and iii) the existence of a multi-

\footnotetext{
${ }^{1}$ See Daniels and Vanhoose (1998) for a recent survey and, among others, Beetsma and Bovenberg (1998), Beetsma et al. (2001), and Buti and Sapir (1998) for a discussion related to the EMU context.

${ }^{2}$ Notwithstanding the consideration of the ECB can sometimes be considered as the introduction of a third player, the generality of the results cannot automatically be extended to a three-country monetary union without further investigations.

'In the deadlock game the non-cooperative strategy is dominant (as in the prisoners' dilemma) and non-cooperative behavior is better than cooperation. Therefore, no rational players will cooperate.

${ }^{4}$ As stressed, e.g., by Turnovsky (1988), Neck and Dockner (1995), and Engwerda et al. (2002).
} 
country context, all in a dynamic set-up. The paper addresses the question how coalitions among fiscal and monetary authorities are formed within the EMU and what are their effects on the stabilization of output and prices. In particular, our attention is directed to study the consequences on these issues of different institutional contexts in which policy-makers may act.

The effects of policy coordination will be studied by using the concepts of strategic bargaining applied to dynamic non-cooperative game theoretic models introduced in the EMU context by van Aarle et al. $(2001 \mathrm{a}, \mathrm{b}) .^{5}$ The formation and consequences of coalitions of policy-makers is one of our main interests and will be investigated by using the recent endogenous coalition formation theory. This recent literature on endogenous coalition studies non-cooperative games where the players can play alone (as a 'singleton') or share their preferences with other players (coalitions). Therefore, this approach is particularly suited to study the interactions among players in environments where externalities occur. ${ }^{6}$

This paper extends the dynamic two-country EMU model of Engwerda et al. (2002) in two ways. First, we explicitly introduce the issue of endogenous coalitions. Second, the analysis of macroeconomic stabilization policies is extended to a three-country monetary union. More in detail, we use the partitioned game approach of the endogenous coalition formation literature. According to $\mathrm{Yi}$ (1997), this approach consists in reducing a game in normal form to a two-stage game (a partitioned game). In the first stage policy-makers try to form coalitions among them by playing non-cooperatively according to different possible initial assumptions (to which different equilibrium concepts correspond). Afterwards, in the second stage of the game, the coalitions formed (or the singletons) play non-cooperatively in setting their stabilization policies to face an asymmetric shock in a dynamic environment as that described in Engwerda et al. (1999) and (2002).

The model is solved by numerical simulations, which are performed by using "ad hoc" parameter values. This procedure is rather usual in the literature; see e.g. Turnovsky et al. (1988), Hughes Hallett (1987), Neck and Dockner (1995), and Hughes Hallett and Ma (1996). A notable exception is Carraro (1997), who combines model estimation, preference revelation and game simulation in a single experiment by assuming no shift of regime during the period which is considered by him. However, in our case several additional problems prevent econometric estimation, e.g. assumptions about regime shifts are extremely difficult to be formulated, too few data are available, ${ }^{7}$ and, also related to this, it is virtually impossible to determine a long-run equilibrium, which is necessary to define the variables of our model.

\footnotetext{
${ }^{5}$ Early research (e.g. Plasmans and de Zeeuw (1980)) has focused on axiomatic bargaining behavior of a similar issue in a non-cooperative setting.

${ }^{6}$ Examples of such applications are common in the literature on environmental economics (see, e.g., Carraro and Siniscalco (1992) and Carraro (1998)). But, recently, endogenous coalition formation theory has also been applied to contexts which are more similar to that of our paper, e.g., on the formation of trade blocks by Baldwin (1995) and on the formation of a monetary union by Kohler (2002).

${ }^{7}$ The EMU exists only since January 1999.
} 
In our numerical simulations we will consider a model of the EMU based on three countries where the national governments and the ECB have different priorities. The governments are mainly concerned with output stabilization whereas the ECB's primary target (according to art. 105 of its mandate) is price stabilization in the Euro-area. In addition, we introduce deficit stabilization as an explicit objective of the individual governments. By doing this we include the fiscal stringency requirements of the Stability and Growth Pact as an element in the decision making problem of the fiscal authorities. Interest rate smoothing is included in the ECB objectives. In the EMU context it is interesting to analyze how such externally imposed institutional restrictions on policy instruments affect the design of optimal policies and aspects of policy cooperation.

In our model different forms of asymmetry may be investigated: countries may have asymmetric structural model parameters (model asymmetry), policymakers may have different preferences (preference asymmetry), policy-makers may have different bargaining powers (power asymmetry), and, finally, shocks may asymmetrically hit countries (shock asymmetry).

In this paper we restrict our attention to three realistic scenarios where several policy regimes (coalitions among policy-makers) are analyzed:

a) A benchmark three-country monetary union with model and power symmetry. In this case, apart from the shocks, the only form of asymmetry is the different priority placed on output and price stabilization by the governments and the ECB, respectively.

b) A three-country monetary union with model symmetry but power asymmetry, where at least one fiscal authority participating in a fiscal coalition has a lower bargaining power than one of the other participants.

c) A three-country monetary union with model asymmetry (measured by different degrees of openness and competitiveness), characterized by the ECB, two symmetric countries that are more open and more exposed to competitiveness than a third country.

Regarding the preference asymmetry, we always assume that the fiscal authorities have the same preferences (mainly concerning output stabilization), but these preferences will be different from those of the ECB (mainly concerning price stabilization). ${ }^{8}$ Shock asymmetry will always be present as we will explain later.

The rest of the paper is organized as follows. Section 2 proposes a stylized model of macroeconomic stabilization in the EMU. Section 3 analyses coalition formation (coalitions as policy regimes) in the context of macroeconomic stabilization policies in the EMU. To do so, concepts of endogenous coalition formation are introduced. Section 4 develops simulations of numerical examples to provide further insights in the basic mechanisms and intuitions. Section 5 concludes by summarizing the main findings of our analysis. In the Appendix mathematical derivations are gathered.

\footnotetext{
${ }^{8}$ Other cases of preference asymmetries are not introduced for reasons of brevity.
} 


\section{A simple dynamic EMU model}

The following IS-AS three-country model of the EMU is analyzed:

$$
\begin{aligned}
y_{1}(t) & =\eta_{1} f_{1}(t)-\gamma_{1} r_{1}(t)+\delta_{12} s_{1}(t)+\delta_{13} s_{2}(t)+\rho_{12} y_{2}(t)+\rho_{13} y_{3}(t) \\
y_{2}(t) & =\eta_{2} f_{2}(t)-\gamma_{2} r_{2}(t)-\delta_{21} s_{1}(t)+\delta_{23} s_{3}(t)+\rho_{21} y_{1}(t)+\rho_{23} y_{3}(t) \\
y_{3}(t) & =\eta_{3} f_{3}(t)-\gamma_{3} r_{3}(t)-\delta_{31} s_{2}(t)-\delta_{32} s_{3}(t)+\rho_{31} y_{1}(t)+\rho_{32} y_{2}(t) \\
\dot{p}_{1}(t) & =\xi_{1} y_{1}(t) \\
\dot{p}_{2}(t) & =\xi_{2} y_{2}(t) \\
\dot{p}_{3}(t) & =\xi_{3} y_{3}(t)
\end{aligned}
$$

in which $y$ denotes real output, $s$ the competitiveness of a country vis-à-vis an other country (i.e. $s_{1}(t):=p_{2}(t)-p_{1}(t) ; s_{2}(t):=p_{3}(t)-p_{1}(t) ; s_{3}(t):=p_{3}(t)-$ $\left.p_{2}(t)\right), r$ the expected real interest rate, $p$ the price level, $f$ the real fiscal deficit, and $i_{E}$ the common nominal interest rate. All the variables are in logarithms, except for the interest rate which is in percentages, and denote deviations from their long-run equilibrium that has been normalized to zero, for simplicity. A dot above a variable denotes its time derivative. Although the nominal interest rate is the same in the whole Euro area, expected real interest rates can temporarily diverge among countries if expected inflation rates are different. The expected real interest rate in country $i \in\{1,2,3\}^{9}$ is defined as the difference between the common nominal interest rate and the expected inflation in this country, i.e. $r_{i}(t):=i_{E}(t)-\dot{p}_{i}^{e}(t)$. Henceforth, perfect myopic foresight is assumed in this paper, so that, in our deterministic context $\dot{p}_{i}^{e}(t)=\dot{p}_{i}(t)$.

Equations (1) are the IS curves which give the aggregate demand (AD) in each of the EMU countries as a function of competitiveness in intra-EMU trade, the real interest rate, the foreign real outputs and the domestic real fiscal deficit. Equations (2) describe the aggregate supply (AS) in each of the EMU countries. Aggregate supply is assumed to be determined by a simple Phillips curve implied by the existence of some rigidities in the goods and/or labor market in the shortrun. In accordance with our short-run stabilization focus, the effectiveness of fiscal policy is limited to its transitory impact on output through the induced stimulus of the aggregate demand.

The above model can be rewritten in the following reduced form for the real

\footnotetext{
${ }^{9}$ In order to save notation, we will often use $i$ to indicate countries or policy-makers. However, notice the difference with $i_{E}$, which is the common nominal interest rate.
} 
outputs: ${ }^{10}$

$$
\left[\begin{array}{l}
y_{1}(t) \\
y_{2}(t) \\
y_{3}(t)
\end{array}\right]=\left[\begin{array}{lllllll}
b_{11} & b_{12} & b_{13} & a_{11} & a_{12} & a_{13} & c_{1} \\
b_{21} & b_{22} & b_{23} & a_{21} & a_{22} & a_{23} & c_{2} \\
b_{31} & b_{32} & b_{33} & a_{31} & a_{32} & a_{33} & c_{3}
\end{array}\right]\left[\begin{array}{c}
s_{1}(t) \\
s_{2}(t) \\
s_{3}(t) \\
f_{1}(t) \\
f_{2}(t) \\
f_{3}(t) \\
i_{E}(t)
\end{array}\right]
$$

The dynamics of the model can then be represented by the following system of first-order linear differential equations with the competitiveness variables $s_{i}(t)$ for $i=\{1,2,3\}$ as the state variables, and the national real fiscal deficits $f_{i}(t)$ and the common nominal interest rate $i_{E}(t)$ as control variables:

$$
\left[\begin{array}{c}
\dot{s}_{1}(t) \\
\dot{s}_{2}(t) \\
\dot{s}_{3}(t)
\end{array}\right]=A\left[\begin{array}{c}
s_{1}(t) \\
s_{2}(t) \\
s_{3}(t)
\end{array}\right]+B_{1} f_{1}(t)+B_{2} f_{2}(t)+B_{3} f_{3}(t)+B_{E} i_{E}(t)
$$

The initial value of the state variables $s_{1}, s_{2}$ and $s_{3}$ measures any initial disequilibrium in competitiveness among the three countries. Such an initial disequilibrium in competitiveness could be the result of differences in fiscal policies in the past or some initial supply side (price) disturbance in some countries.

We assume that the fiscal authorities control their fiscal policy instrument such as to minimize the following quadratic loss function which features domestic inflation, real output and real fiscal deficit with respect to the control variable $f_{i}$ :

$$
J_{i}\left(t_{0}\right)=\frac{1}{2} \int_{t_{0}}^{\infty}\left\{\alpha_{i} \dot{p}_{i}^{2}(t)+\beta_{i} y_{i}^{2}(t)+\chi_{i} f_{i}^{2}(t)\right\} e^{-\theta\left(t-t_{0}\right)} d t
$$

in which $\theta$ denotes the rate of time preference and $\alpha_{i}, \beta_{i}$ and $\chi_{i}$ represent preference weights that are attached to the stabilization of inflation, output and fiscal discipline, respectively. The fiscal instrument in the countries' loss function may reflect the possibility that excessive deficits in the EMU will be subject to sanctions, as proposed in the "Excessive Deficit Procedure" of the Treaty of Maastricht on the European Union (art. 104c), which was signed in 1991, and its more recent extension to the Stability and Growth Pact in 1997. Therefore, countries will prefer low fiscal deficits to high deficits. Another way to formulate this is that the Stability and Growth Pact introduces deficit stabilization, or deficit smoothing, as an explicit objective of fiscal policy design. More in general, costs could also result from undesirable debt accumulation and intergenerational

\footnotetext{
${ }^{10}$ See the Appendix for the highly non-linear specification of the reduced form parameters as a function of the structural form parameters of equations (1) and (2). Notice that the matrix coefficients in the reduced form model (3) are the real output elasticities with respect to the state and control variables of the model.
} 
redistribution that high deficits imply and, in that interpretation, $\chi_{i}$ could also reflect the priority attached to fiscal retrenchment and consolidation.

As stipulated in the Maastricht Treaty, the ECB directs the common monetary policy at stabilizing prices and, as long as not in contradiction to price stabilization, stabilizing output in the aggregate EMU economy. An important question concerns the (mix of) monetary policy instruments operated by the ECB. In particular the discussions have centered around the distinction between an interest rate targeting strategy and a monetary targeting strategy. ${ }^{11}$ In the first case the short-term interest rate is the main policy instrument, in the second case some monetary aggregate is targeted by the ECB. While both strategies will in principle have broadly the same effects, their exact transmissions are somewhat different. ${ }^{12}$ Since interest rate targeting policies and interest smoothing objectives are currently receiving much attention in monetary policy analysis (see e.g. Taylor (1999) and Sack (2000)), we choose the EMU-wide nominal interest rate as the ECB's monetary policy instrument and add an interest rate smoothing objective in ECB's cost function e.g. to express the ECB's caution in setting the monetary policy. Consequently, we assume that the ECB is confronted with the following optimization problem:

$$
\min _{i_{E}} J_{E}\left(t_{0}\right)=\min _{i_{E}} \frac{1}{2} \int_{t_{0}}^{\infty}\left\{\dot{p}_{E}^{2}(t)+y_{E}^{2}(t)+\chi_{E} i_{E}^{2}(t)\right\} e^{-\theta\left(t-t_{0}\right)} d t
$$

where $\dot{p}_{E}:=\sum_{i=1}^{3} \alpha_{E i} \dot{p}_{i}$ and $y_{E}:=\sum_{i=1}^{3} \beta_{E i} y_{i} ; \alpha_{E i}$ and $\beta_{E i}$ indicate the relative weights of country $i$ 's inflation and output in the average inflation and output considered by the ECB.

The policy-makers' loss function can be rewritten as:

$$
J^{i}\left(t_{0}\right)=\frac{d_{i}}{2} \int_{t_{0}}^{\infty}\left\{x^{\top}(t) M_{i} x(t)\right\} e^{-\theta\left(t-t_{0}\right)} d t \quad i \in\{1,2,3, E\}
$$

where $x^{\top}(t):=\left[s_{1}(t), s_{2}(t), s_{3}(t), f_{1}(t), f_{2}(t), f_{3}(t), i_{E}(t)\right], d_{j}:=\alpha_{j} \xi_{j}^{2}+\beta_{j}$ for $j \in\{1,2,3\}, d_{E}:=1$, and $M_{i}$ are coefficient matrices defined in the Appendix.

\footnotetext{
${ }^{11}$ Inflation (forecast) targeting has also been proposed as a third alternative monetary policy strategy. According to this strategy a central bank compares the inflation forecast for some periods ahead (e.g. two years), which is conditional on the actual short-term interest rate, with its inflation target. If the forecast exceeds the target, the short-term interest rate must be raised and vice versa. However, inflation (forecast) targeting does not imply a fully transparent monetary policy since inflation forecasts are provided by the central bank. Hence, the inflation (forecast) targeting is not further explored in this paper. In static models this monetary strategy has, however, been discussed in more detail for the EMU (see e.g. Svensson (1999)).

${ }^{12}$ In the monetary targeting case, the common money supply is exogenous and it is assumed to be the (sole) policy instrument of the ECB. The common interest rate then clears the common money market. In the interest rate targeting case, the common nominal interest rate is assumed to be the (sole) policy instrument of the ECB and the common money market is cleared by adjustments in the money supply. In Engwerda et al. (1999) the ECB implements a monetary targeting strategy, whereas in van Aarle et al. $(2001 \mathrm{a}, \mathrm{b})$ the ECB adopts an interest rate targeting strategy.
} 
Henceforth, for reasons of convenience, we assume that $t_{0}=0$ and $\theta$ is equal to zero. $^{13}$

\section{Policy Coordination: A Coalition Formation Approach}

The issue of coalition formation is analyzed by using the partitioned game approach, which reduces a game in normal form to a two-stage game (a partitioned game). In the first stage policy-makers try to form coalitions among them by playing non-cooperatively. In the second stage of the game, the coalitions formed (or the singletons) play non-cooperatively in setting their stabilization policies to face an asymmetric shock.

Unfortunately, game theory is far from having achieved a well-defined noncooperative theory of coalition formation. Therefore, there are several stability concepts that can be used and that provide different equilibrium coalition structures. Different possible ways to model the endogenous coalition formation could be helpful in deriving some indications about the optimal institutional design of the EMU area. In fact, according to Ecchia and Mariotti (1997), different equilibrium concepts can be seen as different institutional contexts where policy-makers act. Such a kind of investigation might be particularly interesting in the current European debate where the "final asset" of the EMU is still under discussion.

More in detail, the possible candidate equilibrium concepts for the first stage of the game can be grouped in three main categories.

1. The standard Nash equilibrium concept introduced in the coalition literature by the seminal studies of d'Aspremont et al. (1983) in the industrial organization literature and its several variants as surveyed in Carraro (1998).

2. The equilibrium concepts related to a sequential entry approach (Sequential Negotiation Equilibrium). ${ }^{14}$ With such an approach, one player after the other decides to propose a coalition to the other players. These decisions are determined by non-cooperative best-reply rules, given the coalition structure and the allocation in the previous rounds. One of the nice features of this approach is that it might explain in terms of history why specific stable coalitions are reached among the many possible ones. In other words, the importance of historical relationships between nations might be captured by this approach.

\footnotetext{
${ }^{13}$ Assuming $\theta$ different from zero, the model could easily be solved following the procedure used in this paper after a simple transformation of variables, i.e. transforming $x(t)$ into $e^{-\frac{1}{2} \theta t} x(t)$ and substituting $A$ by $A-\frac{1}{2} \theta I$ where $I \in \mathbb{R}^{3 \times 3}$ is a diagonal matrix with ones on the main diagonal (see Engwerda et al. (1999), p.263, for further details).

${ }^{14}$ See, e.g., Bloch (1996) and Ray and Vohra (1999).
} 
3. The solution concepts based on the idea of indirect domination, which implies farsightedness (Farsighted Coalitional Equilibrium; see, e.g., Chwe (1994), and Mariotti (1998)). The indirect domination concept captures the idea that each agent (or coalition of agents), who deviates from a given coalition structure, has anticipated further deviations of other agents. ${ }^{15}$

In this paper we focus on the first kind of solution concepts for reasons of brevity and to keep the model simple. However, some intuitions based on an informal discussion of the effects of the other two strands of solution concepts will also be presented.

The second stage of the game (when coalitions have already been formed) is solved by using the open-loop Nash equilibrium concept as presented in the previous section. ${ }^{16}$.

To formalize possible types of coordination behavior among policy-makers, we have to introduce some additional notation. We call a coalition any nonempty subset of the policy-makers' set (i.e. the set formed by all policy-makers $\{1,2,3, E\})$. Moreover, we assume that policy-makers in a coalition cooperatively set their instruments in order to minimize a common loss function, i.e. a convex combination of their respective loss functions. A coalition structure is a partition of the policy-makers' set into coalitions. Therefore, each coalition structure is associated with a policy regime, i.e. which policy-makers are cooperating and which are not.

Indicating by $\omega_{i}$ a generic element (coalition) of the coalition structure $\Omega$ (policy regime), we can formally represent the policy coordination game for each given policy regime as obtaining the (open-loop) Nash equilibrium of the differential game defined by the system (4) of differential equations and by the loss function(s):

$$
J_{i}(t)=\frac{1}{2} \int_{t_{0}}^{\infty}\left\{\sum_{j \in \omega_{i}} \tau_{j} d_{j} x^{\top}(t) M_{j} x(t)\right\} d t \quad \forall \omega_{i} \in \Omega, \forall j \in \omega_{i}
$$

\footnotetext{
${ }^{15}$ More in detail, according to Ecchia and Mariotti (1998), a multi-stage negotiation procedure that implies farsightedness can be described informally in the following way. At each stage, a coalition structure (strategy profile) is the current status quo. Then, one policymakers' coalition may be formed and different sets of strategies may be proposed so that another status quo can be reached. If somebody else (either a policy-makers' coalition or a single policy-maker) deviates from the status quo, all members of that coalition are free to propose to deviate further. The deviating coalition may be the same initial coalition. This means that there is no permanent commitment: agreements between member policy-makers are no longer binding when the status quo changes. The policy-makers are only interested in the loss associated with a permanent status quo. So, the process continues in this way until there is a status quo from which nobody wishes to deviate. At this point coalitions are defined. Hence, the farsightedness characteristic replaces the Nash myopic behavior by a longer-term horizon.

${ }^{16}$ We assume that there does not exist a transfer mechanism which compensates those agents who may loose by joining (leaving) the coalition (e.g. side-payments). However, the existence of a transfer mechanism does not seem to be compatible with the EMU context. This does not mean that transfer mechanisms cannot be analyzed (see e.g. Casella (1999) and Engwerda et al. (2002)). These are not considered here, also for reasons of conciseness.
} 
where $J_{i}(t)$ is the loss function of the coalition $\omega_{i}$ and $\tau_{j}$ is the policy-maker $j$ 's bargaining weight in the coalition $\omega_{i} .{ }^{17}$ The number of coalitions acting in each regime is clearly equal to the cardinality of $\Omega$, for example if $\Omega$ is equal to $\{(1,2,3), E\}$, the number of coalitions is equal to 2 and $J_{1}(t)$ is the loss associated with the (full) fiscal coalition while $J_{2}(t)$ is that associated with the ECB.

The minimization of the loss function(s) (8) subject to the system (4) of differential equations yields the following optimal controls:

$$
\left(\begin{array}{c}
f_{1}(t) \\
f_{2}(t) \\
f_{3}(t) \\
i_{E}(t)
\end{array}\right)=: \Psi(\Omega) s(t) .
$$

where $s^{\top}(t):=\left[s_{1}(t), s_{2}(t), s_{3}(t)\right]$ with the initial disequilibrium $s(0)=: s_{0} \in \mathbb{R}^{3}$, and the matrix $\Psi(\Omega)$ is computed via the eigenstructure of a matrix that is determined by the coalition structure $\Omega$ (see Appendix).

Note that according to (9) the optimal strategies are a linear feedback rule on the state variables and are moreover depending on the coalition structure in place. The resulting (optimal) losses that policy-makers incur equal:

$$
J_{(\omega)}^{i}=\frac{d_{i}}{2} \int_{t_{0}}^{\infty}\left\{s^{\top}(t)\left[I, \Psi(\Omega)^{\top}\right] M_{i}\left(\begin{array}{c}
I \\
\Psi(\Omega)
\end{array}\right) s(t)\right\} d t
$$

for $i \in\{1,2,3, E\}$.

Using the policy-makers' optimal costs (10), we will consider the following policy regimes:

(a) The non-cooperative solution $\{1,2,3, E\}$, where no policy coordination occurs.

(b) The grand coalition $\{(1,2,3, E)\}$, where all policies are set in a cooperative manner.

(c) The full fiscal coalition $\{(1,2,3), E\}$ and the partial fiscal coalitions: $\{(1,2)$, $3, E\},\{(1,3), 2, E\}$ and $\{1,(2,3), E\}$, where some (or all governments) agree to coordinate the setting of their fiscal policy.

Partial coalitions involving the ECB and one or two countries are not considered for the following reasons. First, the ECB is a common institution. Therefore, partial coalitions between the ECB and only some countries in the Euro area are, in principle, difficult to justify. Second, previous studies (see van Aarle et al. $(2001 \mathrm{a}, \mathrm{b}))$ show that, in general, these coalitions are in most cases unlikely to arise since they imply losses for the coalition members being higher than those associated with the non-cooperative solution. Third, considering

\footnotetext{
${ }^{17} \mathrm{It}$ is trivial that when $\omega_{i}$ is a singleton $\tau_{j}=1$ and when equal bargaining powers are assumed $\tau_{j}$ is equal to 1 divided by the cardinality of $\omega_{i}$.
} 
also the coalition involving the ECB notably increases the number of possible coalitions with another twelve policy regimes affecting the compact exposition of the results.

As said above, we mainly restrict our attention to the first mechanism of coalition formation: the coalitional Nash equilibrium (CNE), although other solution concepts (sequential and farsightedness equilibria) will also briefly be discussed. A CNE is an equilibrium of a one-shot game where agents simultaneously face the problem of accepting or rejecting a proposal that consists in sharing their loss function and cooperatively setting their instruments. After that all agents' decisions are taken, the CNE is formed. More formally the CNE is characterized by two properties:

1. Profitability property. The losses in the coalition must be lower than or equal to the non-cooperative losses for all coalition members.

2. Stability property: (a) internal stability: the loss of each coalition member must be lower than or equal to the loss that the same policy-maker faces when she defects from the coalition and the other members do not change their strategies; (b) external stability: the losses of each non-coalition member must be lower than the losses that the policy-maker faces when she joins the coalition. ${ }^{18}$ A coalition (structure) is said to be stable if it is both internally and externally stable.

Profitability assures that the coalition is convenient for its members, while stability guarantees that the equilibrium is self-enforcing. A CNE is based on the following assumption: when leaving (joining) a coalition, each agent assumes that the other agents are not changing their strategies. In other words, this assumption is equivalent to the assumption of the Nash conjectures in a simultaneous oligopoly game where a player assumes no change in the other players' decision variable(s) when she modifies her own decision variable(s). ${ }^{19}$ Under the assumption that non-members can join an existing coalition without the permission of the existing members (open membership assumption), profitability and stability completely characterize a CNE equilibrium.

Coalition theory often uses other assumptions as exclusive membership and coalition unanimity (Bloch (1997)). Exclusive membership means that potential coalition members cannot enter the coalition without the permission of the coalition members. In this case, an equilibrium is characterized by the profitability and the internal stability properties. Assuming coalition unanimity means that the whole coalition is assumed to collapse when one of its members defects. Hence, an equilibrium under unanimity is fully characterized by profitability only. Notice that in the EMU context most economic policy measures should be decided by all the members through a qualified or unanimous majority.

\footnotetext{
${ }^{18}$ Yi (1997) denotes this condition by the term "stand alone stable".

${ }^{19}$ The above definition of stability coincides with the definition of a stable cartel provided in the oligopoly literature (see d'Aspremont et al. (1983)).
} 


\section{Numerical simulations}

\subsection{The scenarios}

We investigate three possible realistic scenarios where all policy regimes defined in the previous section are considered.

I In the first scenario we assume a monetary union with model and power symmetry (symmetric countries). This scenario basically represents the extension to a three-country case of the two-country model considered by van Aarle et al. (2001a,b) in a similar game.

II In the second scenario we assume a monetary union with model symmetry but power asymmetry (e.g. large vs. small countries). More in particular, one fiscal authority (small country) has a lower bargaining power than the other two fiscal authorities (large countries).

III Finally, we consider the case of a monetary union with model asymmetry (different degrees of openness and competitiveness), which is characterized by two symmetric countries that are more open and more exposed to competitiveness than a third country.

In all the numerical simulations we assume that the governments' priority is real output stabilization while the ECB, which equally weighs all countries, is mainly concerned about price stabilization. In particular, the fiscal policymakers are assumed to have the same preferences but, in general, policy-makers will have different preferences (preference asymmetry). More in detail, the policy-makers' preferences are assumed to be described by the following values: $\alpha=0.2, \alpha_{E}=0.8, \beta=0.4, \beta_{E}=0.3, \chi=0.15$, and $\theta=0.15$. Moreover, the initial state of the EMU area is assumed to be equal to $s_{0}^{\top}=[0.05,0,-0.05]$. This initial state corresponds to the case of an asymmetric price shock in the EMU (shock asymmetry) where, initially, prices in country 2 are $5 \%$ higher than in the two other countries. This implies that the low-price countries 1 and 3 initially face favorable terms of trade with respect to the high-price country 2 , and therefore, real output deviations will be positive in the low-price countries and negative in the high-price one. The other parameters used in the numerical simulations, as well as the results of our experiments, are described in detail in the following subsections.

Notice that, considering the shock asymmetry, the first benchmark scenario shows two full symmetric countries (countries 1 and 3) whereas scenarios II and III involve that all countries are asymmetric. In fact, in the second scenario countries 1 and 3 differ from country 2 according to the initial price shock, but country 1 differs from country 3 with respect to the bargaining power (power asymmetry). In the third scenario, countries 1 and 3 again differ from country 2 because of (at least) the initial price shock, but country 1 differs from country 3 with respect to the structural parameters (model asymmetry). Hence, our three-country approach really extends the two-country model of the kind as in Engwerda et al. (2002). 


\subsection{Scenario I - Symmetric countries (model symmetry)}

In the first scenario, the structural (form) parameters are assumed to be the same for all the countries (model symmetry) with the following values: the aggregate demand elasticity $\eta$ with respect to the real fiscal deficit is assumed to be equal to 1 , the output semi-elasticity $\gamma$ of the real interest rate is assumed to be 0.4 , the output elasticity $\delta$ of competitiveness is assumed to be 0.2 , the output elasticity $\rho$ of foreign output (degree of openness) is assumed to be 0.4 , and the Phillips curve coefficient $\xi$, which measures the extent of nominal rigidities, is assumed to be 0.25. All the policy-makers are assumed to have the same bargaining power when they cooperate (power symmetry). In this scenario, the sole form of asymmetry is related to the price shock (shock asymmetry) which makes the (high-price) country 2 different from the other two symmetric (low-price) countries.

Table 1 presents the results of our first numerical simulation. These results widely reflect the model and power symmetries assumed. As in a two-country model (see e.g. van Aarle et al. (2001b)), where these kinds of symmetries are considered, there is no difference between the grand coalition $C$ and the full fiscal coalition $F$. This occurs because of two characteristics of this scenario related to the symmetry assumptions. First, as shown in figures 1 and 2 below, the fiscal policies of the low-price (high-output) countries are exactly offset by the fiscal policy of the other country, due to the model symmetry and the preference symmetry among fiscal authorities. Second, due to the model symmetry, the ECB does not affect the dynamics of the competitiveness since changes in the common nominal interest rate equally affect all the prices. Results dramatically change when partial fiscal coalitions are formed, even in this symmetric setting. With partial fiscal coalitions all the players, including the ECB, are directly affected in their optimal policies and losses. However, since countries 1 and 3 (low-price countries) face the same shock their optimal losses are the same (or symmetric in the partial coalitions with the country which suffers from high prices).

\section{[around here table 1]}

In all the regimes, the higher-price country suffers from higher optimal costs since it faces a positive price shock (increase in price) while the other two countries face a negative price shock. Consequently, the ECB will mainly pursue an restrictive monetary policy in order to stabilize the output (prices) in the low-price countries.

Profitable regimes are the fiscal regime $F$ (and the grand coalition $C$ ) and the partial coalitions between the high-price country and one of the other two $((1,2)$ and $(2,3))$, while the coalition between the low-price countries $(1,3)$ is not profitable. This result seems to confirm that fiscal coordination is counterproductive unless asymmetries are present. In fact, in the case of cooperation between two symmetric countries that face the same kind of price shock (fully symmetric countries), cooperation increases the countries' optimal losses. This result, which is often observed for the two-country models, is due to the central 
bank's action, which offsets that of the fiscal players. ${ }^{20}$ Cooperation between countries that face asymmetric shocks (i.e. all the coalitions where the highprice country is included) is profitable. Related to this observation, in a threecountry context, cooperation between symmetric countries becomes profitable if they also cooperate with a third asymmetric country.

Regarding the stability property, all the profitable coalitions are internally stable but only the full fiscal coalition (and the grand coalition) is also externally stable. Therefore, the full fiscal and the grand coalitions are the CNE of the game. This result derives from the following two characteristics of the numerical simulation. First, the ECB cannot neutralize the cooperation among fiscal players (if they are not all fully symmetric). Second, free-riding behavior is not optimal for the fiscal players since, when they leave the full fiscal coalition, they suffer higher (optimal) costs.

Considering different games of endogenous coalition formation (e.g. sequential entry or farsightedness), it is easy to argue that the final equilibrium will always be the full fiscal coalition (or the grand coalition) since it is the first best for all the policy-makers.

\section{[around here figure 1 and 2]}

The adjustment of the macroeconomic variables under the non-cooperative and the cooperative ${ }^{21}$ regimes are reported in figures 1 and 2 , respectively. In both regimes, the ECB is inactive, the fiscal policies in the low-price (highoutput) countries 1 and 3 are restrictive, whereas the high-price (low-output) country 2 chooses a fiscal expansion policy. However, when policy-makers cooperate in order to internalize the externalities, the governments of the lowprice countries pursue less restrictive fiscal policies, whereas country 2's fiscal authority pursues a less expansionary fiscal policy than that pursued in the noncooperative case. The effects of the cooperation are higher volatilities (spreads) of output and inflation in all countries. Therefore, the reason of the lower losses associated with cooperative regimes has to be found in the more moderate use of the fiscal instruments.

\subsection{Scenario II - Large vs. small countries (power asym- metry)}

Table 2 describes the results of our second numerical simulation where we investigate the power distribution among EMU policy-makers. We consider the same situation depicted in the previous numerical simulation (model symmetry), but now we assume that country 3 has always a lower bargaining power when it cooperates with the (an) other policy-maker(s) (power asymmetry). ${ }^{22}$ More in

\footnotetext{
${ }^{20}$ The robustness of this result was verified with respect to a broad set of model parameters.

${ }^{21}$ Since in this scenario the full fiscal and the grand coalitions coincide, we speak of cooperative regime to indicate both of them.

${ }^{22}$ The bargaining power of a country can be assumed to be an increasing function of its relative size (e.g. the share of its GDP with respect to the aggregate GDP of the EMU).
} 
detail, country 3 (the small country) is assumed to have a bargaining power equal to $\frac{1}{5}$ in the grand coalition regime (while the other players share the rest, i.e. each of them has a bargaining power equal to $\left.\frac{\left(1-\frac{1}{5}\right)}{3}\right)$, the small country's bargaining power is assumed to be equal to $\frac{1}{4}$ in the full fiscal regime (others $\frac{3}{8}$ ), and it is assumed to be equal to $\frac{1}{3}$ when the small country cooperates with one of the other countries $\left(\frac{2}{3}\right)$. Of course, the (optimal) losses associated with the non-cooperative regime and the coalition between the large country 1 and the large and high-price country 2 are the same as in table 1 . In this scenario, all the countries are asymmetric through the combination of the power and the shock asymmetries.

As in the previous scenario the coalition between countries 1 and 3 is not profitable. But, differently from table 1 , the coalition between the large highprice country and the small low-price country $(2,3)$ is not profitable. In fact, due to the different bargaining power distribution, the coalition among the highprice and the small countries does not show the symmetric (optimal) losses of that between the large countries (compare the optimal losses of fiscal coalitions $(1,2)$ and $(2,3)$ in tables 1 and 2$)$.

[around here table 2]

The coalition between the two large countries $(1,2)$ is internally stable but externally unstable since there is an incentive for the small country to join the coalition. If the ECB is not allowed to participate to a coalition, the fiscal regime $F$ is both internally and externally stable, and therefore, it is the CNE of the game since it is also profitable. But if the ECB can join the full fiscal coalition, the full fiscal coalition is not externally stable any longer. The equilibrium, in this case, turns out to the non-cooperative equilibrium since if the low-price large country (country 1) leaves the grand coalition, it achieves a lower (optimal) loss (recall that if country 1 leaves the coalition, the ECB is also assumed to leave it). ${ }^{23}$

The asymmetric distribution of the bargaining power yields two effects: it reduces the willingness to cooperate of the low bargaining power country and it redistributes the (optimal) losses among the coalition members in the different policy regimes. The first effect tends to increase the instability of the coalitions while the second tends to reduce their profitability.

In order to understand the complexity of the policy-makers' interactions, note that if coalition members can block the entry of other policy-makers (exclusive membership assumption), the coalition $(1,2)$ between the two large countries also becomes an equilibrium of the game since the (large) high-price country 2 can prevent that the small country 3 enters this coalition. Similarly, the full fiscal coalition becomes an equilibrium since the fiscal authorities can prevent that the ECB enters the coalition. Considering the unanimity assumption (i.e. all profitable coalitions are an equilibrium), the number of equilibria increases

\footnotetext{
${ }^{23}$ Note that the CNE is the first best for the low-price countries 1 and 3, while the high-price (large) country prefers the grand coalition.
} 
since three policy regimes are profitable, i.e. the grand coalition $C$, the full fiscal coalition $F$, and the partial fiscal coalition $(1,2)$. The effects of farsightedness are also notable. In our example, consideration about farsightedness does not enforce the full cooperation, as usual. In fact, in our case, when policy-makers deviate from profitable but unstable coalitions, they always join a stable and profitable coalition structure. ${ }^{24}$

[around here figure 3]

The adjustment of the macroeconomic variables under the non-cooperative and the full fiscal cooperative regimes can be compared by looking at figures 1 and 4 . In both regimes, the fiscal policies in low-price (high-output) countries 1 and 3 are restrictive, and the fiscal policy in the high-price country 2 is expansionary. When the full fiscal cooperation is considered all fiscal policies are smoothed (i.e. restrictive policies become less restrictive and expansionary policies become less expansionary), but the ECB is no longer inactive, ${ }^{25}$ as in the non-cooperative case, since, the fiscal policies of countries 1 and 3 do not exactly compensate that of country 2 because of the power asymmetry. The effects of cooperation on macroeconomic variables is similar to that exposed in figure 2, where the equal bargaining power case is depicted. However, since asymmetric bargaining powers are assumed asymmetric differences in the (optimal) individual losses of the national fiscal authorities are due to the ECB intervention.

\subsection{Scenario III - Different openness and competitiveness (model asymmetry)}

In the third scenario, we remove the assumption of model symmetry. We consider the following changes in the structural (form) parameters presented in our first two scenarios. Countries 2 and 3 are assumed to be subject to a high structural form output elasticity of competitiveness vis-à-vis country 1 $\left(\delta_{21}=\delta_{31}=0.4\right.$; other $\delta s$ are assumed to remain the same at a value of 0.2$)$. Changes in country 1's income are assumed to have a strong impact on the other countries $\left(\rho_{21}=\rho_{31}=0.5\right)$ but income changes in countries 2 and 3 are assumed to have marginal effects on country $1\left(\rho_{12}=\rho_{13}=0.1\right)$. Changes in the income of countries 2 and 3 are assumed to have a moderate effect on the income of the other country $\left(\rho_{23}=\rho_{32}=0.3\right)$. These parameters imply that countries 2 and 3 are (relatively) more open and are more exposed to international competitiveness within EMU than country 1. The above parameterization implies several structural externalities because of the changes in the output elasticities of openness and competitiveness. An equal bargaining power (power symmetry)

\footnotetext{
${ }^{24}$ However, further simulations, not reported here, show that increasing the bargaining power asymmetry, the incentive to deviate rises and, in this case, if profitability is still satisfied, farsightedness reinforces the (full) fiscal regime and the grand coalition solutions. See also van Aarle et al. (2001a) for the two-country case.

${ }^{25}$ Monetary policy becomes tightening.
} 
and the same asymmetric price shock (shock asymmetry) as in the previous two numerical simulations are assumed. Therefore, all the countries are asymmetric through the combination of the model and the shock asymmetries.

Table 3 describes the results of our final numerical simulation.

$$
\text { [around here figure 3] }
$$

Despite the fact that several asymmetries are present, no coalitions are profitable. This means that the unique CNE is the non-cooperative regime, which is not the first best for any of the policy-makers. The effects of cooperation on the policy-makers' (optimal) losses are rather complex. All the cooperative regimes are profitable for the high-price country 2 , but all the coalitions including country 2 imply higher (optimal) losses for the other participant(s). The sole profitable coalition for the low-price (open) country 3 is the partial coalition with the other low-price country 1 . However, the optimal strategy of country 1 is to free-ride since its optimal strategy is always to avoid cooperation with the other policy-makers. ${ }^{26}$

The adjustment of the macroeconomic variables associated with the noncooperative regime is described in figure 4. Since the country one's restrictive fiscal policy has a large negative effect on the outputs of countries 2 and 3 , the ECB follows an expansionary monetary policy. The figure 4 clearly illustrates that model asymmetries imply a very different (optimal) behavior of the policymakers.

$$
\text { [around here figure 4] }
$$

Taking into account the other endogenous coalition formation games, the lack of profitability implies that a solution being different from the non-cooperative one will never emerge. Therefore, under this parameterization, the non-cooperative result is quite robust with respect to different specifications of the coalition formation process (e.g. exclusive membership, sequential entry or farsightedness).

The ultimate non-cooperative result seems to show that the existence of asymmetries is a necessary condition to observe gains in the cooperation but it is not a sufficient condition.

\section{Concluding remarks}

This paper focuses on how coalitions among fiscal and monetary authorities are formed and what are their effects on the stabilization of output and inflation. In doing that, we introduce a novelty in the literature by combining the following two aspects of policy coordination:

(a) macroeconomic stabilization policies of individual countries and a common central bank of a monetary union are considered in a three-country dynamic model,

\footnotetext{
${ }^{26}$ The first best policy regime (coalition structure) for country 1 is the fiscal coalition between the fiscal authorities of the other two (more open) countries.
} 
(b) coalition formation among policy-makers to coordinate their policies is explicitly considered by using the recent approach of endogenous coalition formation theory.

More in detail, our paper extends the dynamic two-country EMU model of Engwerda et al. (2002) by using the partitioned game approach of the endogenous coalition formation literature. This approach consists in reducing a game in normal form to a two-stage game. In the first stage policy-makers try to form coalitions among them by playing non-cooperatively according to different possible initial assumptions (to which correspond different equilibrium concepts). Afterwards, in the second stage of the game, the coalitions formed (or the individual policy-makers) play non-cooperatively in setting their stabilization policies to face an asymmetric shock in a dynamic environment.

Coordination of (national) fiscal policies and (a common) monetary policy was then investigated through several numerical simulations where we have concentrated our attention on the role played by asymmetries (in structural and preference parameters) and externalities, which are the key to endogenously explain the coalition formation.

We have considered three scenarios for numerical simulations: i) a monetary union composed by three symmetric countries, that face an asymmetric shock, ii) a monetary union where a small country interacts with two large countries, that face an asymmetric shock, and iii) a monetary union composed of two (relatively) open countries that face an asymmetric shock, and interact with a (relatively) closed country. From our numerical simulations five major conclusions can be derived.

1. Regimes different from the grand coalition, the full fiscal coalition, and the non-cooperative regime are never an equilibrium of the game. In fact, the full fiscal coalition is always the equilibrium in the first scenario and it is also so in the second scenario according to some equilibrium concepts only, whereas the grand coalition is an equilibrium only in the first case (where it coincides with the full fiscal coalition because of the symmetries). In the third scenario, the non-cooperative regime is the equilibrium of the game for all equilibrium concepts considered.

2. As for the static two-country models, fiscal coordination seems to be counter-productive unless asymmetries are present. In fact, in the first scenario countries want to cooperate only if they are subject to asymmetric shocks. However, considering three countries, two symmetric countries can benefit from cooperation if they coordinate their fiscal instrument with that of a third asymmetric country.

3. In our benchmark case (the first scenario) cooperation always implies the lowest losses for all fiscal authorities without affecting the optimal cost of the ECB. Therefore, it turns out to be the equilibrium of the game irrespective of the equilibrium concept that is used to solve the game. 
4. Under asymmetric bargaining powers (scenario two) the full fiscal coalition differs from the grand coalition and the equilibrium of the game depends on the assumptions considered. However, the grand coalition is never an equilibrium of the game, whereas the full fiscal coalition is an equilibrium (but not unique) under the unanimity and exclusive membership assumptions.

5. In the third scenario, the less open and less exposed to intra-EMU competition country always wants to free-ride and does not want to cooperate with the more open and exposed counties. Furthermore, the more open and exposed counties do not want to cooperate with each other. Hence, this scenario, where many asymmetric externalities are present, illustrates that the existence of asymmetries and externalities is a necessary but not sufficient condition for cooperation since the unique equilibrium is the non-cooperative solution.

We think that this latter observation deserves further attention, so that we would like to investigate the impact of the sign and the size of spillovers on coordination in the near future. In addition, we would like to explicitly consider different equilibrium concepts and study how they are related to the institutional setting of the EMU. 


\section{Appendix}

\section{Reduced form of the model}

Defining the following matrices:

$$
\begin{aligned}
& m_{1}^{\top}:=\left(\begin{array}{c}
b_{11} \\
b_{12} \\
b_{13} \\
a_{11} \\
a_{12} \\
a_{13} \\
c_{1}
\end{array}\right):=\Delta_{1}\left(\begin{array}{c}
\delta_{12}-\frac{\rho_{12} k_{3} \delta_{21}+\rho_{13} \rho_{32} \delta_{21}}{k_{3} k_{2}-\rho_{32} \rho_{23}} \\
\delta_{13}-\frac{\rho_{12} \rho_{23} \delta_{31}+\rho_{13} k_{2} \delta_{31}}{k_{3} k_{2}-\rho_{32} \rho_{23}} \\
\frac{\rho_{13}\left(\rho_{32} \delta_{23}-k_{2} \delta_{32}\right)-\rho_{12}\left(\rho_{23} \delta_{32}-k_{3} \delta_{23}\right)}{k_{3} k_{2}-\rho_{32} \rho_{23}} \\
\eta_{1} \\
\frac{\rho_{12} k_{3} \eta_{2}+\rho_{13} \rho_{32} \eta_{2}}{k_{3} k_{2}-\rho_{32} \rho_{23}} \\
\frac{\rho_{12} \rho_{23} \eta_{3}+\rho_{13} k_{2} \eta_{3}}{k_{3} k_{2}-\rho_{32} \rho_{23}} \\
-\gamma_{1}-\frac{\rho_{12}\left(\gamma_{2} k_{3}+\gamma_{3} \rho_{23}\right)+\rho_{13}\left(\gamma_{3} k_{2}+\gamma_{2} \rho_{32}\right)}{k_{2} k_{3}-\rho_{23} \rho_{32}}
\end{array}\right) \\
& m_{2}^{\top}:=\left(\begin{array}{l}
b_{21} \\
b_{22} \\
b_{23} \\
a_{21} \\
a_{22} \\
a_{23} \\
c_{2}
\end{array}\right):=\Delta_{2}\left(\begin{array}{c}
-\delta_{21}-\frac{\rho_{21} k_{3} \delta_{12}+\rho_{23} \rho_{31} \delta_{12}}{k_{3} k_{1}-\rho_{31} \rho_{13}} \\
\frac{\rho_{23}\left(\rho_{31} \delta_{13}-k_{1} \delta_{31}\right)-\rho_{21}\left(\rho_{13} \delta_{31}-k_{3} \delta_{13}\right)}{k_{3} k_{1}-\rho_{31} \rho_{13}} \\
\delta_{23}-\frac{\rho_{21} \rho_{13} \delta_{32}+\rho_{23} k_{1} \delta_{32}}{k_{3} k_{2}-\rho_{32} \rho_{23}} \\
\frac{\rho_{21} k_{3} \eta_{1}+\rho_{23} \rho_{31} \eta_{1}}{k_{3} k_{1}-\rho_{31} \rho_{13}} \\
\frac{\rho_{21} k_{3} \eta_{1}+\rho_{23} \rho_{31} \eta_{1}}{k_{3} k_{1}-\rho_{31} \rho_{13}} \\
\frac{\rho_{21} \rho_{13} \eta_{3}+\rho_{23} k_{1} \eta_{3}}{k_{3} k_{1}-\rho_{31} \rho_{13}} \\
-\gamma_{2}-\frac{\rho_{21}\left(\gamma_{1} k_{3}+\gamma_{3} \rho_{33}+\rho_{23}\left(\gamma_{3} k_{1}+\gamma_{1} \rho_{31}\right)\right.}{k_{1} k_{3}-\rho_{13} \rho_{31}}
\end{array}\right) \\
& m_{3}^{\top}:=\left(\begin{array}{c}
b_{31} \\
b_{32} \\
b_{33} \\
a_{31} \\
a_{32} \\
a_{33} \\
c_{3}
\end{array}\right):=\Delta_{3}\left(\begin{array}{c}
\frac{\rho_{31}\left(k_{2} \delta_{12}-\rho_{12} \delta_{21}\right)+\rho_{32}\left(\rho_{21} \delta_{12}-k_{1} \delta_{21}\right)}{k_{2} k_{1}-\rho_{21} \rho_{12}} \\
-\delta_{31}+\frac{\rho_{31} k_{2} \delta_{13}+\rho_{32} \rho_{21} \delta_{13}}{k_{2} k_{1}-\rho_{21} \rho_{12}} \\
-\delta_{32}+\frac{\rho_{31} \rho_{12} \delta_{23}+\rho_{32} k_{1} \delta_{23}}{k_{2} k_{1}-\rho_{21} \rho_{12}} \\
\frac{\rho_{31} k_{2} \eta_{1}+\rho_{32} \rho_{21} \eta_{1}}{k_{2} k_{1}-\rho_{21} \rho_{12}} \\
\frac{\rho_{31} \rho_{12} \eta_{2}+\rho_{32} k_{1} \eta_{2}}{k_{2} k_{1}-\rho_{21} \rho_{12}} \\
\eta_{3} \\
-\gamma_{3}-\frac{\rho_{31}\left(\gamma_{1} k_{2}+\gamma_{2} \rho_{12}\right)+\rho_{32}\left(\gamma_{2} k_{1}+\gamma_{1} \rho_{21}\right)}{k_{1} k_{2}-\rho_{12} \rho_{21}}
\end{array}\right)
\end{aligned}
$$

where $k_{i}:=1-\gamma_{i} \xi_{i}$ for $i \in\{1,2,3\}$ and

$$
\left(\begin{array}{c}
\Delta_{1} \\
\Delta_{2} \\
\Delta_{3}
\end{array}\right):=\left(\begin{array}{l}
\frac{k_{3} k_{2}-\rho_{32} \rho_{23}}{k_{1}\left(k_{3} k_{2}-\rho_{32} \rho_{23}\right)-\rho_{12}\left(k_{3} \rho_{21}+\rho_{23} \rho_{31}\right)-\rho_{13}\left(k_{1} \rho_{31}+\rho_{31} \rho_{21}\right)} \\
\frac{k_{3} k_{1}-\rho_{31} \rho_{13}}{k_{2}\left(k_{3} k_{1}-\rho_{31} \rho_{13}\right)-\rho_{21}\left(k_{3} \rho_{12}+\rho_{13} \rho_{32}\right)-\rho_{23}\left(k_{1} \rho_{32}+\rho_{31} \rho_{12}\right)} \\
\frac{k_{2} k_{1}-\rho_{21} \rho_{12}}{k_{3}\left(k_{2} k_{1}-\rho_{21} \rho_{12}\right)-\rho_{31}\left(k_{2} \rho_{13}+\rho_{12} \rho_{23}\right)-\rho_{32}\left(k_{1} \rho_{23}+\rho_{21} \rho_{13}\right)}
\end{array}\right),
$$

we can rewrite the reduced form equations for real outputs as:

$$
\begin{aligned}
& y_{1}(t)=: m_{1} x(t) \\
& y_{2}(t)=: m_{2} x(t) \\
& y_{2}(t)=: m_{3} x(t)
\end{aligned}
$$


with $x^{\top}(t):=\left[s_{1}(t), s_{2}(t), s_{3}(t), f_{1}(t), f_{2}(t), f_{3}(t), i_{E}(t)\right]$.

The coefficients of the dynamic law of motion of the system $\dot{s}(t)=A s(t)+$ $\sum_{i=1}^{3} B_{i} f_{i}(t)+B_{E} i_{E}(t)$ are then given by the following expression:

$$
\begin{gathered}
{\left[\begin{array}{c}
\dot{s}_{1}(t) \\
\dot{s}_{2}(t) \\
\dot{s}_{3}(t)
\end{array}\right]=} \\
+\left[\begin{array}{lll}
\xi_{2} b_{21}-\xi_{1} b_{11} & \xi_{2} b_{22}-\xi_{1} b_{12} & \xi_{2} b_{23}-\xi_{1} b_{13} \\
\xi_{3} b_{31}-\xi_{1} b_{11} & \xi_{3} b_{32}-\xi_{1} b_{12} & \xi_{3} b_{33}-\xi_{1} b_{13} \\
\xi_{3} b_{31}-\xi_{2} b_{21} & \xi_{3} b_{32}-\xi_{2} b_{22} & \xi_{3} b_{33}-\xi_{2} b_{23}
\end{array}\right]\left[\begin{array}{l}
s_{1}(t) \\
s_{2}(t) \\
s_{3}(t)
\end{array}\right]+ \\
+\left[\begin{array}{l}
\xi_{2} a_{21}-\xi_{1} a_{11} \\
\xi_{3} a_{31}-\xi_{1} a_{11} \\
\xi_{3} a_{31}-\xi_{2} a_{21}
\end{array}\right] f_{1}(t)+\left[\begin{array}{l}
\xi_{2} a_{22}-\xi_{1} a_{12} \\
\xi_{3} a_{32}-\xi_{1} a_{12} \\
\xi_{3} a_{32}-\xi_{2} a_{22}
\end{array}\right] f_{2}(t)+ \\
+\left[\begin{array}{l}
\xi_{2} a_{23}-\xi_{1} a_{13} \\
\xi_{3} a_{33}-\xi_{1} a_{13} \\
\xi_{3} a_{33}-\xi_{2} a_{23}
\end{array}\right] f_{3}(t)+\left[\begin{array}{l}
\xi_{2} c_{2}-\xi_{1} c_{1} \\
\xi_{3} c_{3}-\xi_{1} c_{1} \\
\xi_{3} c_{3}-\xi_{2} c_{2}
\end{array}\right] i_{E}(t) .
\end{gathered}
$$

After some tedious algebra,we can rewrite the government $i$ 's loss function as:

$$
\begin{gathered}
J_{i}=\frac{1}{2} \int_{t_{0}}^{\infty}\left\{\alpha_{i} \dot{p}_{i}^{2}(t)+\beta_{i} y_{i}^{2}(t)+\chi_{E} i_{E}^{2}(t)\right\} e^{-\theta\left(t-t_{0}\right)} d t= \\
=\frac{1}{2}\left(\alpha_{i} \xi_{i}^{2}+\beta_{i}\right) \int_{t_{0}}^{\infty}\left\{x^{\top}(t)\left(m_{i}^{\top} m_{i}+\frac{\chi_{i}}{d_{i}} e_{i+1}^{\top} e_{i+1}\right) x(t)\right\} e^{-\theta\left(t-t_{0}\right)} d t= \\
=\frac{1}{2}\left(\alpha_{i} \xi_{i}^{2}+\beta_{i}\right) \int_{t_{0}}^{\infty}\left\{x^{\top}(t) M_{i} x(t)\right\} e^{-\theta\left(t-t_{0}\right)} d t
\end{gathered}
$$

where $e_{i}$ is a vector with all entries equal to zero, except for entry $i$ that is equal to one.

Similarly, we can rewrite the ECB's loss function as:

$$
\begin{gathered}
J_{E}=\frac{1}{2} \int_{t_{0}}^{\infty}\left\{\left(\sum_{i=1}^{3} \alpha_{i E} \dot{p}_{i}(t)\right)^{2}+\left(\sum_{i=1}^{3} \beta_{i E} y_{i}(t)\right)^{2}+\chi_{E} i_{E}^{2}(t)\right\} e^{-\theta\left(t-t_{0}\right)} d t= \\
=\frac{1}{2} \int_{t_{0}}^{\infty}\left\{\left(\sum_{i=1}^{3} \alpha_{i E} \xi y_{i}(t)\right)^{2}+\left(\sum_{i=1}^{3} \beta_{i E} y_{i}(t)\right)^{2}+\chi_{E} i_{E}^{2}(t)\right\} e^{-\theta\left(t-t_{0}\right)} d t= \\
=\frac{1}{2} \int_{t_{0}}^{\infty}\left\{\left(\sum_{i=1}^{3} \alpha_{i E} \xi m_{i} x(t)\right)^{2}+\left(\sum_{i=1}^{3} \beta_{i E} m_{i} x(t)\right)^{2}+\chi_{E} i_{E}^{2}(t)\right\} e^{-\theta\left(t-t_{0}\right)} d t= \\
=\frac{1}{2} \int_{t_{0}}^{\infty}\left\{x^{\top}(t) M_{E} x(t)\right\} e^{-\theta\left(t-t_{0}\right)} d t
\end{gathered}
$$

where $M_{E}:=\left(\sum_{i=1}^{3} \alpha_{i E} \xi m_{i}^{T} x(t)^{T}\right)\left(\sum_{i=1}^{3} \alpha_{i E} \xi m_{i} x(t)\right)+\left(\sum_{i=1}^{3} \beta_{i E} m_{i}^{T} x^{T}(t)\right)$ $\left(\sum_{i=1}^{3} \beta_{i E} m_{i} x(t)\right)+\chi_{E} x(t)^{\top} e_{5}^{\top} e_{5} x(t)$. 


\section{The basic algorithm to derive the game solutions}

The algorithm is described by the following 5 steps.

1. Factorize matrices $M_{i}$ as

$$
M_{i}=\left(\begin{array}{ccccc}
Q_{i} & P_{i} & L_{i} & K_{i} & S_{i} \\
P_{i}^{\top} & R_{1 i} & N_{i} & H_{i} & T_{i} \\
L_{i}^{\top} & N_{i}^{\top} & R_{2 i} & F_{i} & V_{i} \\
K_{i}^{\top} & H_{i}^{\top} & F_{i}^{\top} & R_{3 i} & W_{i} \\
S_{i}^{\top} & T_{i}^{\top} & V_{i}^{\top} & W_{i}^{\top} & R_{4 i}
\end{array}\right)
$$

for $i \in\{1,2,3, E\}$, where $Q_{i} \in \mathbb{R}^{3 \times 3} ; P_{i}, L_{i}, K_{i} \in \mathbb{R}^{3 \times 3} ;$ and the other coefficients are scalars.

2. Compute the following matrices:

$$
\begin{aligned}
G & :=\left(\begin{array}{cccc}
R_{11} & N_{1} & M_{1} & T_{1} \\
N_{2}^{\top} & R_{22} & F_{2} & V_{2} \\
H_{3}^{\top} & F_{3}^{\top} & R_{33} & W_{3} \\
T_{E}^{\top} & V_{E}^{\top} & W_{E}^{\top} & R_{4 E}
\end{array}\right) \\
H_{1}: & =\left(\begin{array}{ccccc}
-A & 0 & 0 & 0 & 0 \\
Q_{1} & A^{\top} & 0 & 0 & 0 \\
Q_{2} & 0 & A^{\top} & 0 & 0 \\
Q_{3} & 0 & 0 & A^{\top} & 0 \\
Q_{E} & 0 & 0 & 0 & A^{\top}
\end{array}\right) \\
H_{2}:= & \left(\begin{array}{ccccc}
B_{1} & B_{2} & B_{3} & B_{E} \\
-P_{1} & -L_{1} & -K_{1} & -S_{1} \\
-P_{2} & -L_{2} & -K_{2} & -S_{2} \\
-P_{3} & -L_{3} & -K_{3} & -S_{3} \\
-P_{E} & -L_{E} & -K_{E} & -S_{E}
\end{array}\right) \\
H_{3}: & =\left(\begin{array}{ccccc}
P_{1}^{\top} & B_{1}^{\top} & 0 & 0 & 0 \\
L_{2}^{\top} & 0 & B_{2}^{\top} & 0 & 0 \\
K_{3}^{\top} & 0 & 0 & B_{3}^{\top} & 0 \\
S_{E}^{\top} & 0 & 0 & O & B_{E}^{\top}
\end{array}\right)
\end{aligned}
$$




$$
M=H_{1}+H_{2} G^{-1} H_{3}
$$

4. After computing the eigenstructure of $M$, take three positive eigenvalues and the corresponding eigenvectors $v_{i}$ (for $i \in\{1,2,3\}$ ) to write the following expression: ${ }^{27}$

$$
\left(\begin{array}{c}
X \\
Y_{1} \\
Y_{2} \\
Y_{3} \\
Y_{4}
\end{array}\right):=\left(\begin{array}{lll}
v_{1} & v_{2} & v_{3}
\end{array}\right):=z \in \mathbb{R}^{4 \times 3}
$$

from which we can derive the optimal controls:

$$
\left(\begin{array}{c}
f_{1} \\
f_{2} \\
f_{3} \\
i_{E}
\end{array}\right)=-G^{-1}\left(\begin{array}{c}
P_{1}^{\top}+B_{1}^{\top} C L_{1} \\
L_{2}^{\top}+B_{2}^{\top} C L_{2} \\
K_{3}^{\top}+B_{3}^{\top} C L_{3} \\
S_{E}^{\top}+B_{E}^{\top} C L_{4}
\end{array}\right) s=: C L s
$$

where $C L_{i}:=Y_{i} X^{-1}$.

5. Rewrite the cost functions of the policy-makers and the dynamics of the model as $J_{i}=\frac{1}{2} \int_{0}^{\infty} s^{\top}\left[\left(I, C L^{\top}\right) M_{i}\left(\begin{array}{c}I \\ C L\end{array}\right)\right] s d t$ and $\dot{s}=(A+B C L) s=$ : $A_{C L} s$, respectively. The problem is then solved by considering:

$$
J_{i}=s_{0}^{\top} X_{i} s_{0}
$$

where $X_{i}$ solves the following Lyapunov equation:

$$
A_{C L}^{\top} X_{i}+X_{i} A_{C L}+\frac{1}{2}\left(I, C L^{\top}\right) M_{i}\left(\begin{array}{c}
I \\
C L
\end{array}\right)=0
$$

Cooperative solutions are achieved by using the same algorithm and factorizing $M_{i}$ matrix in a similar way as in van Aarle et al. (2001b).

\footnotetext{
${ }^{27}$ If matrix $M$ has more than three positive eigenvalues multiple equilibria arise, whereas if this matrix has less than three positive eigenvalues no equilibrium exists (for more details see Engwerda (1998)).
} 
Table 1 - Optimal Costs (multiplied by 1,000$)^{28}$

\begin{tabular}{ccccccc}
\hline & $N C$ & $C$ & $F$ & $(1,2)$ & $(1,3)$ & $(2,3)$ \\
Country 1 & 0.7092 & 0.4911 & 0.4911 & 0.5470 & 0.8067 & 0.6883 \\
Country 2 & 2.8368 & 1.9642 & 1.9642 & 2.0661 & 2.7533 & 2.0661 \\
Country 3 & 0.7092 & 0.4911 & 0.4911 & 0.6883 & 0.8067 & 0.5470 \\
ECB & 0 & 0 & 0 & 0.0035 & 0.0140 & 0.0035 \\
Average & - & 0.7368 & 0.9821 & 1.3066 & 0.8067 & 1.3066 \\
\hline
\end{tabular}

Table 2 - Optimal costs (multiplied by 1,000 )

\begin{tabular}{|c|c|c|c|c|c|c|}
\hline & $N C$ & $\bar{C}$ & $F$ & $(1,2)$ & $(1,3)$ & $(2,3)$ \\
\hline Country 1 & 0.7092 & 0.5370 & 0.4355 & 0.5470 & 0.7364 & 0.4564 \\
\hline Country 2 & 2.8368 & 1.8760 & 2.1058 & 2.0661 & 2.6462 & 2.6363 \\
\hline Country 3 & 0.7092 & 0.5372 & 0.4448 & 0.6883 & 1.2475 & 1.1444 \\
\hline ECB & 0 & 0.0020 & 0.0627 & 0.0035 & 0.0752 & 0.6798 \\
\hline Average & - & 0.7380 & 0.9954 & 1.3066 & 0.9919 & 1.8904 \\
\hline \multicolumn{7}{|c|}{ Table 3 - Optimal costs (multiplied by 1,000 ) } \\
\hline & $N C$ & $C$ & $F$ & $(1,2)$ & $(1,3)$ & $(2,3)$ \\
\hline Country 1 & 0.6197 & 0.6918 & 0.6206 & 0.9572 & 0.7740 & 0.5164 \\
\hline Country 2 & 4.5840 & 3.5406 & 3.7709 & 3.6855 & 4.7241 & 2.0314 \\
\hline Country 3 & 0.5487 & 0.6759 & 0.5912 & 0.7560 & 0.5166 & 1.9514 \\
\hline ECB & 0.0161 & 0.0246 & 0.0013 & 0.0177 & 0.0520 & 0.0104 \\
\hline Average & - & 1.2332 & 1.6609 & 2.3214 & 0.6453 & 1.9915 \\
\hline
\end{tabular}
${ }^{28}$ In all the tables, columns identify policy regimes; rows 2 to 5 indicate the policy-makers'
(optimal) losses while row 6 shows the average (optimal) loss of each coalition member. 

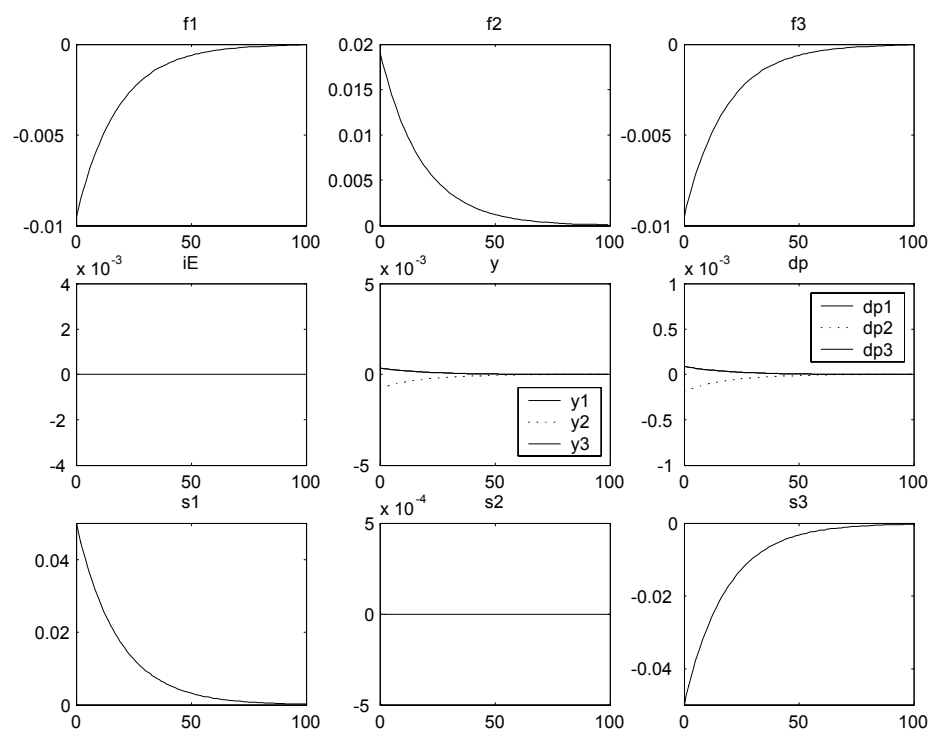

Figure 1 - Non-cooperative regime in scenarios I and II
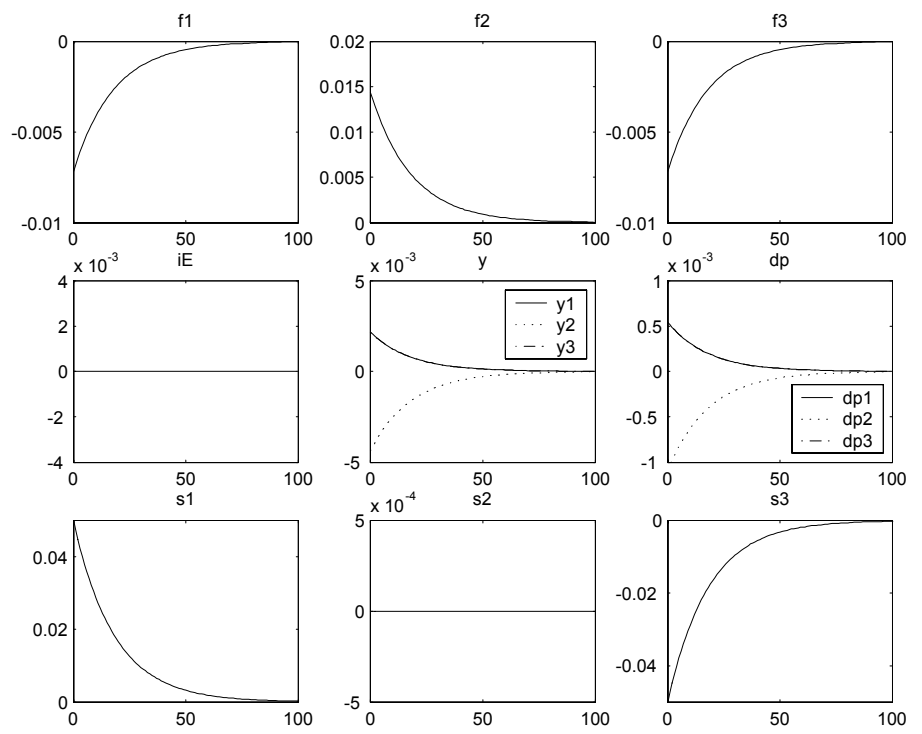

Figure 2 - Cooperative regimes in scenario I 

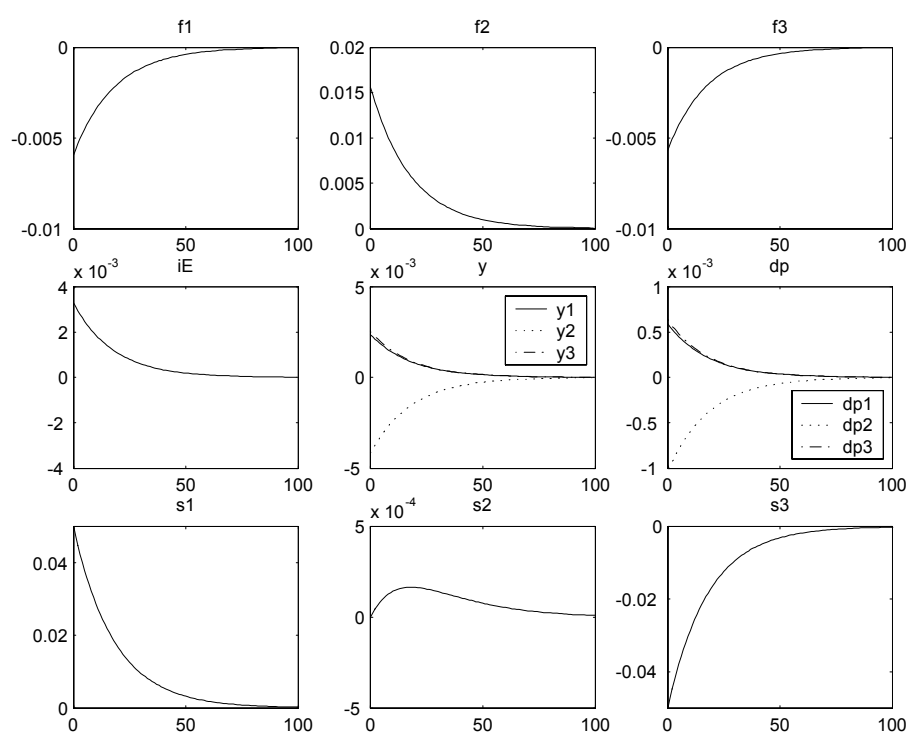

Figure 3 - Full fiscal coalition regime in scenario II
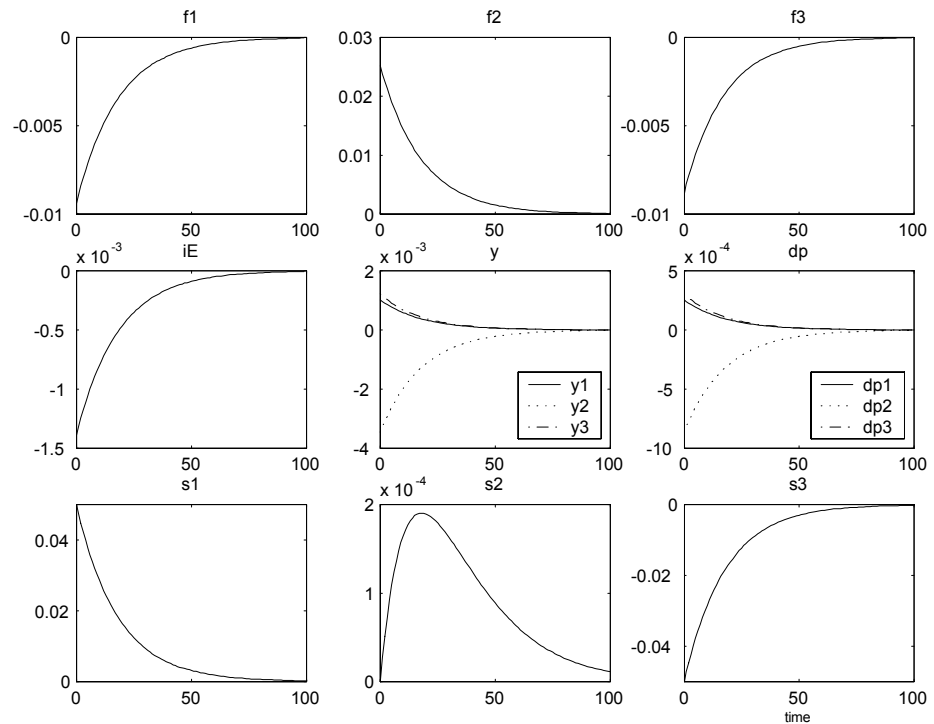

Figure 4 - Non-cooperative regime in scenario III 


\section{References}

Aarle, B. van, G. Di Bartolomeo, J. Engwerda and J. Plasmans (2001a), "Coalitional behaviour in an open-loop LQ differential game for the EMU ", to appear in R. Neck, Modeling and Control of Economic System SME-IFAC Proceedings, Elsevier, Oxford.

Aarle, B. van, J.C. Engwerda and J.E.J. Plasmans (2001b), "Monetary and fiscal policy interaction in the EMU: A dynamic game approach", CESIfo Working Paper No. 437, to appear in Annals of Operations Research.

d'Aspremont, C.A., Jacquemin A., Gabszewicz J.J. and Weymark J. (1983) "On the stability of collusive price leadership", Canadian Journal of Economics, vol. 16, pp. 17-25.

Baldwin, R. (1995), "A domino theory of regionalism", in R. Baldwin, P. Haaparanta and J. Kiander (eds.), Expanding European regionalism: The EU's new members, Cambridge University Press, Cambridge.

Beetsma, R.M.W.J. and Bovenberg A.L. (1998), "Monetary union without fiscal coordination may discipline policymakers?", Journal of International Economics, vol. 45, pp. 239-258.

Beetsma, R.M.W.J., X. Debrun and F. Klaassen (2001), "Is fiscal policy coordination in EMU desirable?", CESIfo Working Paper No. 599, Center for Economic Studies and Ifo Institute for Economic Research, Munich.

Bloch, F. (1996), "Sequential formation of coalitions in games with externalities and fixed payoff division", Games and Economic Behavior, vol. 14, pp. 90123.

Bloch, F. (1997), "Noncooperative models of coalition formation in games with spillovers" in C. Carraro and D. Siniscalco (eds.) New directions in the economic theory of the environment, Cambridge University Press, Cambridge.

Buti M. and A. Sapir, (1998), Economic policy in the EMU - A study by the European Commision services, Claredon Press, Oxford.

Casella, A. (1999), "Tradable deficit permits: Efficient implementation of the Stability Pact in the European Monetary Union", NBER Working Paper No. 7278 .

Carraro, C. (1997), "Modelling international policy games: Lessons from European monetary coordination", Empirica, vol. 24, pp. 163-177.

Carraro, C. (1998), "International Environmental Agreements : Incentives and Political Economy", European Economic Review, vol. 42, pp. 561-572.

Carraro, C. and D. Siniscalco (1992), "The international dimension of environmental policy", European Economic Review, vol. 36, no. 2-3, pp. 379-387. 
Chwe, M.S. (1994), "Farsighted coalitional stability", Journal of Economic Theory, vol. 54, pp. 299-325.

Daniels, J.P. and D.D. Vanhoose (1998), "Two-country models of monetary and fiscal policy: What have we learned? What more can we learn?", Open Economies Review, vol. 9, pp. 263-82.

Ecchia, G. and M. Mariotti (1998), "Coalition formation in international environmental agreements and the role of institutions", European Economic Review, vol. 42, pp. 573-582.

Engwerda, J.C. (1998), "Computational aspects of the open-loop Nash equilibrium in linear quadratic games", Journal of Economic Dynamics and Control, vol. 22, pp. 1487-1506.

Engwerda, J.C., B. van Aarle and J.E.J. Plasmans (1999), "The (in)finite horizon open-loop Nash LQ game: An application to the EMU", Annals of Operations Research, vol. 88, pp. 251-273.

Engwerda, J.C., B. van Aarle and J.E.J. Plasmans (2002), "Cooperative and non-cooperative fiscal stabilisation policies in the EMU", Journal of Economic Dynamics and Control, vol. 26, pp. 451-81.

Hughes Hallet, A.J. (1987), "Optimal policy design in interdependent economies" in C. Carraro and D. Sartore (eds.), Developments of control theory for economic analysis, Kluwer Academic Publishers, Dordrecht.

Hughes Hallett, A.J. and Y. Ma (1996), "Changing partners: the importance of coordinating fiscal and monetary policies within a monetary union", The Manchester School of Economic and Social Studies, vol. 64, pp. 115-34.

Kehoe, T. (1988), "Policy coordination among benevolent governments may be undesiderable", Review of Economic Studies, vol. 56, pp. 289-296.

Kohler, M (2002), "Coalition Formation in International Monetary Policy Games", Journal of International Economics, vol. 56, pp. 371-385.

Mariotti, M. (1998), "A model of agreements in a strategic form games", Journal of Economic Theory, vol. 73, pp. 128-139.

Neck, R. and E.J. Dockner (1995), "Commitment and coordination in a dynamic game model of international economic policy-making", Open Economies Review, vol. 6 , pp. 5-28.

Plasmans, J.E.J. and A.J. de Zeeuw (1980), "Incentives to cooperate in linear quadratic difference games", International Journal of Systems Science, vol. 11, no. 5, pp. 607-619.

Ray, D. and R. Vohra (1999). "A theory of endogenous coalition structures", Games and Economic Behavior, vol. 26, pp. 286-336. 
Rogoff, K. (1985), "Can international monetary cooperation be couterproductive", Journal of International Economics, vol. 18, pp. 199-217.

Sack, B. (2000), "Does the Fed act gradually? A VAR analysis", Journal of Monetary Economics, vol.461, pp.229-256.

Svensson, L. (1999), "Monetary policy issues for the Eurosystem", National Bureau of Economic Research Working Paper No. 7177.

Taylor, J.(ed.) (1999), Monetary Policy Rules, University of Chicago Press, Chicago.

Turnovsky, S.J., T. Basar and V. D'Orey (1988), "Dynamic strategic monetary policies and coordination in interdependent economies", American Economic Review, vol. 78, pp. 341-61.

Yi, S. (1997), "Stable Coalition structures with externalities", Games and Economic Behaviour, vol. 20, pp. 201-237. 